\title{
A Novel Ex Vivo Model to Investigate the Underlying Mechanisms in Alzheimer's Disease
}

\author{
Emanuele Brai ${ }^{1 *}$, Skye Stuart ${ }^{1,2}$, Antoine-Scott Badin ${ }^{1}$ and Susan A. Greenfield ${ }^{1}$ \\ ${ }^{1}$ Neuro-Bio Ltd., Culham Science Centre, Abingdon, United Kingdom, ${ }^{2}$ School of Physiology, Pharmacology \\ and Neuroscience, Faculty of Biomedical Sciences, University of Bristol, Bristol, United Kingdom
}

Currently there is no widely accepted animal model reproducing the full pathological profile of Alzheimer's disease (AD), since the basic mechanisms of neurodegeneration are still poorly understood. We have proposed that the interaction between the $\alpha 7$ nicotinic acetylcholine receptor ( $\alpha 7-n A C h R)$ and a recently discovered toxic peptide, cleaved from the acetylcholinesterase (AChE) C-terminus, could account for the aberrant processes occurring in $A D$. In this article we describe a new application on ex vivo model procedure, which combines the advantages of both in vivo and in vitro preparations, to study the effects of the AChE-derived peptide on the rat basal forebrain (BF). Western blot analysis showed that the levels of $\alpha 7-n A C h R, p-T a u$ and $A \beta$ are differentially expressed upon the AChE-peptide administration, in a selective site-dependent manner. In conclusion, this methodology demonstrates the action of a novel peptide in triggering an AD-like phenotype and proposes a new ex vivo approach for manipulating and monitoring neurochemical processes contributing to neurodegeneration, in a time-dependent and site-specific manner.

\section{OPEN ACCESS}

Edited by: Rosanna Parlato,

University of UIm, Germany

Reviewed by:

Cláudia Fragão Pereira,

University of Coimbra, Portugal Viola Nordström,

Deutsches Krebsforschungszentrum (DKFZ), Germany

*Correspondence:

Emanuele Brai

emanuele.brai@neuro-bio.com

Received: 23 June 2017 Accepted: 04 September 2017 Published: 20 September 2017

Citation:

Brai E, Stuart S, Badin A-S and Greenfield SA (2017) A Novel Ex Vivo Model to Investigate the Underlying Mechanisms in Alzheimer's Disease.

Front. Cell. Neurosci. 11:291. doi: 10.3389/fncel.2017.00291
Keywords: Alzheimer's disease, basal forebrain, ex vivo brain slices, AChE-peptide, $\alpha 7-n A C h R, p-T a u, A \beta$

\section{INTRODUCTION}

Alzheimer's disease (AD) is the most common form of dementia, but the primary events promoting this disorder remain still unidentified. The most popular "amyloid hypothesis" is now being increasingly challenged (Herrup, 2015; Small and Greenfield, 2015; De Strooper and Karran, 2016) and an alternative theory compatible with all clinical features is needed. A new hypothesis suggests that the basic mechanisms of neurodegeneration may occur in a group of neurons which are specifically and primarily vulnerable in AD (Arendt et al., 1992, 2015; Auld et al., 2002; Mesulam, 2004; Schliebs and Arendt, 2011; Schmitz et al., 2016). This heterogeneous neuronal network constitutes a continuous hub of adjacent cell groups, which extend from the basal forebrain (BF) to midbrain and brainstem, areas projecting to key brain areas such as cortex, hippocampus and olfactory bulb (Mesulam et al., 1983). Although this core of susceptible cells display a variety of transmitters, they share the expression of the enzyme acetylcholinesterase (AChE), now established to exert a non-cholinergic function (Greenfield, 2013; Garcia-Ratés et al., 2016). This non-enzymatic role consists in modulating calcium influx into neurons (Greenfield, 2013; Garcia-Ratés et al., 2016) and hence it has trophic or toxic actions depending on dose, availability and neuronal age. In $\mathrm{AD}$ therefore, cell death could be attributable to this non-hydrolytic action (Greenfield and Vaux, 2002; Greenfield, 2013; Garcia-Ratés et al., 2016), more specifically via a 14mer peptide cleaved from the AChE C-terminus and included within a more stable, larger peptide, T30 (Greenfield and Vaux, 2002). In addition, the AChE-derived peptide shares a sequence homology 
with A $\beta$ (Greenfield, 2013; Garcia-Ratés et al., 2016). In AD brains, its concentration is doubled and in PC12 cell lines drives the production of $\mathrm{p}$-Tau and $\mathrm{A} \beta$ (Garcia-Ratés et al., 2016) via its binding to the $\alpha 7$ nicotinic acetylcholine receptor ( $\alpha 7-\mathrm{nAChR}$ ) and consequent modulation of calcium entry (Greenfield and Vaux, 2002; Greenfield et al., 2004; Bond et al., 2009; GarciaRatés et al., 2016). Furthermore, this nicotinic receptor is upregulated upon T30 application in cell cultures (Bond et al., 2009).

Thus, the aims of this work are: (1) describe a novel approach using ex vivo brain slices to investigate the early stages occurring during neurodegeneration in intact tissue, whilst maintaining the local neuronal circuitry of the appropriate region and providing the possibility of monitoring acute responses; and (2) evaluate the effects of $\mathrm{T} 30$ in a more physiological scenario, ex vivo rat brain slices, analyzing its impact on $\alpha 7-n A C h R$, p-Tau and $A \beta$ expression. T30 has been applied at a concentration of $2 \mu \mathrm{M}$, since this dose was previously administered on the same BF containing sections showing to reduce the neuronal activity via optical imaging experiments (Badin et al., 2016). This methodology could be applied to study diverse molecular cascades, to test pharmacological compounds and provide a reliable tool for drug screening, thereby reducing the number of experiments on living animals.

\section{MATERIALS AND EQUIPMENTS}

\section{Animals}

Nine wild type P14 male Wistar rats were used for this study. This work was performed following the experimental procedures approved by the Home Office (UK) in the guidance on the operation of the Animals (Scientific Procedures) Act 1986 and European guidelines on animal experimentation. The animals were sacrificed respecting Schedule 1 methods (humane killing methods) listed in the Act, which covers all elements of animal research in the UK.

\section{Reagents for Artificial Cerebrospinal Fluids (aCSFs) Preparation}

- Sodium chloride (NaCl; Sigma-Aldrich, S7653, Germany)

- Potassium chloride (KCl; Sigma-Aldrich, P9333, Germany)

- Sodium bicarbonate $\left(\mathrm{NaHCO}_{3}\right.$; Sigma-Aldrich, S5761, Germany)

- Magnesium sulfate heptahydrate $\left(\mathrm{MgSO}_{4}\left(7 \mathrm{H}_{2} \mathrm{O}\right)\right.$; SigmaAldrich, 63138, Germany)

- Potassium phosphate monobasic $\left(\mathrm{KH}_{2} \mathrm{PO}_{4}\right.$; Sigma-Aldrich, P5655, Germany)

- Hepes salt (Sigma-Aldrich, H7006, Germany)

- Hepes acid (Sigma-Aldrich, H3375, Germany)

- Glucose (Sigma-Aldrich, G7528, Germany)

- Calcium chloride dehydrate (Sigma-Aldrich, 223506, Germany)

- T30 (Genosphere Biotechnologies, France)

These reagents are used to obtain the stock solutions $5 \times$ Krebs, $5 \times$ Hepes and Sodium bicarbonate in order to prepare the "slicing" aCSF and the "recording" aCSF.
The final concentrations, in mmol, of the two aCSFs (previously described from Badin et al., 2013) are for the "slicing" aCSF: $120 \mathrm{NaCl}, 5 \mathrm{KCl}, 20 \mathrm{NaHCO}_{3}, 2.4 \mathrm{CaCl}_{2}, 2 \mathrm{MgSO}_{4}$, $1.2 \mathrm{KH}_{2} \mathrm{PO}_{4}$ and 10 glucose; 6.7 HEPES salt and 3.3 HEPES acid; pH: 7.1. "Recording" aCSF: $124 \mathrm{NaCl}, 3.7 \mathrm{KCl}, 26 \mathrm{NaHCO}_{3}$, $2 \mathrm{CaCl}_{2}, 1.3 \mathrm{MgSO}_{4}, 1.3 \mathrm{KH}_{2} \mathrm{PO}_{4}$ and 10 glucose; $\mathrm{pH}$ : 7.1 .

\section{Equipments and Reagents for Brain Dissection, Slicing, Incubation and Homogenization}

- Plastic box

- Isoflurane (Henry Schein, cat\# 200-070, USA)

- Guillotine

- aCSFs

- Surgical dissecting kit (World Precision Instruments, Item\#: MOUSEKIT, USA)

- Surgical blades (Swann-Morton, BS 2982, UK)

- Spatula

- Glue

- Filter paper (Fisher, cat\#11566873, USA)

- Vibratome (Leica, VT1000 S, Germany)

- Brushes

- Icebox

- Oxygen canister

- Apparatus (see "Materials and Procedure for the Apparatus Building" Below)

- $1 \times$ Phosphate buffer saline (PBS, Fisher, cat\# BP2438-4, USA)

- Phosphatase inhibitors (Fisher, cat\# 1284-1650, USA)

- Protease inhibitors (Roche complete PIC, 04693116001, USA)

- Pestles (Starlab, cat\# I1415-5390, UK)

- Microcentrifuge tubes $1.5-2 \mathrm{ml}$

\section{Materials and Procedure for the Apparatus Building}

1. Plastic box

2. Air flow control valves (Altec Products Ltd., UK).

3. 2 bundling ties (Altec Products Ltd., UK).

4. Three different sizes PVC tubing. One with a $5 \mathrm{~mm}$ bore (cat\# 01-94-1584), three pieces with a $3 \mathrm{~mm}$ bore (cat\# 01-941580) and six pieces with a $1.5 \mathrm{~mm}$ bore (cat\# 116-0536-19) (Altec Products Ltd., UK).

5. One straight barbed and three barbed Y connectors (ColeParmer, UK)

6. Glue

7. 12 Hypodermic needles (six $21 \mathrm{G}$, green, and six 25G, orange) (BD Microlance, UK)

8. Six $20 \mathrm{~mm}$ injection stopper (Adelphi Healthcare Packaging, INJW20RTS, 1071, UK)

9. Six $5 \mathrm{ml}$ Schott tubular glass Injection vials (Adelphi Healthcare Packaging, VC005-20C, UK)

10. Support

Fix the (2) to the (1) using (3) (Figure 1K). Connect to one end of the (2) the $5 \mathrm{~mm}$ bore tubing (4) which is linked to the oxygen source through the straight barbed connector (5) (Figure 1L). Attach to the lower outlet of the valves the $3 \mathrm{~mm}$ bore tubing (Figure $\mathbf{1 K}$ ). After, insert the three barbed 

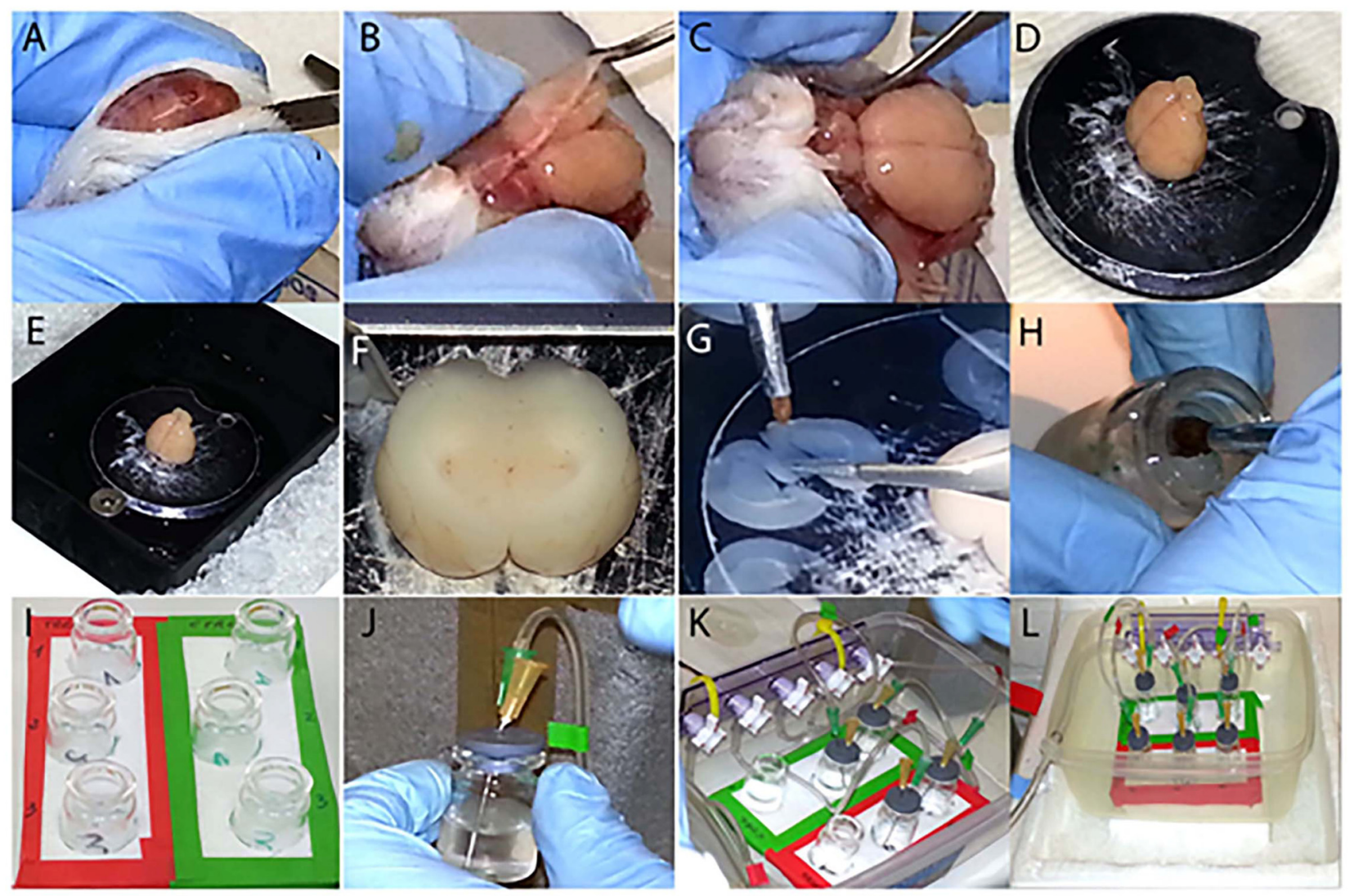

FIGURE 1 | Step by step visualization of the experimental preparation. (A-C) Dissection of the brain from the skull. (D) Gluing the brain to the vibratome disc. (E) The outer buffer-chamber is ice cooled, while the inner part containing the brain is filled with ice cold "slicing" aCSF. (F) Sectioning of the brain in coronal slices containing the basal forebrain (BF). (G) Division of the slices in two complementary hemisections. (H) Disposal of each hemisection in its corresponding vial. (I) Three hemisections are transferred into the control group vials (green label), whereas their matching counterparts are placed into the treated group vials (red label). $\mathbf{( J , K ) ~ E a c h ~ v i a l ~ i s ~ i n d i v i d u a l l y ~ s e a l e d ~} \mathbf{( J )}$ and placed into the support (K). (L) Set up ready for the experiment, connected to the oxygen source and placed on ice.

Y connectors (5) in the other side of the $3 \mathrm{~mm}$ bore tubing. Attach the small tubes ( $1.5 \mathrm{~mm}$ bore) to each Y shaped connector, in order to have two tubes per each valve (Figure 1K). The free edges of these tubes are glued (6) to the $21 \mathrm{G}$ needles (7), which are individually inserted in (8) (Figure 1J), where the 25G needles (7) are also placed. The $25 \mathrm{G}$ needles allow the outflow of oxygen excess from (9). Once all the vials (9) (Figure 1I) are closed (Figures 1J,K) position them in the support (10), connect the apparatus to the oxygen source and start the experiment (Figure 1L).

\section{Western Blot Reagents and Equipment}

- Pierce $660 \mathrm{~nm}$ Protein Assay (Thermo Scientific, cat\# 22660, USA)

- Loading buffer (Bio Rad, cat\# 161-0747, USA)

- Beta-mercaptoethanol (Bio Rad, cat\# 161-0710, USA)

- Ladder (Bio Rad, cat\# 161-0377, USA)

- Running buffer 10× TGS (Fisher, BP1341, cat\# 10102823, USA)

- Transfer Buffer $10 \times$, prepared dissolving Tris Base (Fisher Scientific, BP152-500, USA) and Glycine (Fisher Scientific, BP381-500, USA) in distilled water.
- Tris Buffer Saline, TBS $10 \times$ prepared dissolving Tris Base (Fisher Scientific, BP152-500, USA) and sodium chloride (Sigma-Aldrich, S7653, Germany) in distilled water.

- Tween 20 (Sigma-Aldrich, P9416, Germany)

- Filter paper (Bio Rad, cat\# 1703955, USA)

- PVDF (Immobilon-P) transfer membranes (Sigma-Aldrich, P2563, Germany)

- 4\%-20\% Mini-PROTEAN TGX Precast Protein Gels (Bio Rad, cat\# 456-1094, USA)

- BLOT-FastStain (G-Biosciences, cat\# 786-34, USA)

- Blotting grade blocker (Bio Rad, cat\# 170-6404, USA)

- Mouse anti-phosphorylated Tau (Thermo Fisher, MN1020, UK)

- Mouse anti-Amyloid beta (Absolute Antibody, Ab00239-2.0, UK)

- Rabbit anti- $\alpha 7-n$ AchR (Abcam, ab10096, UK)

- Goat anti mouse HRP conjugated (Sigma-Aldrich, A9309, Germany)

- Goat anti rabbit HRP conjugated (Abcam, ab6721, UK)

- Clarity western ECL substrate (Bio Rad, cat\# 170-5061, USA)

- G-Box Chemi XT Imaging System (Syngene, UK) 


\section{Buffers}

- $1 \times$ PBS

- $1 \times$ TBS Dilute the stock solution (TBS 10 $\times$ ) in distilled water.

- $1 \times$ TBS-Tween $0.05 \%$ (TBST) Dilute the stock solution (TBS $10 \times$ ) in distilled water and add Tween.

- Lysis buffer Dilute in 1× PBS both protein inhibitors 1:100.

\section{STEPWISE PROCEDURES}

\section{Brain Dissection, Slicing and Experimental Procedure}

Rats were sacrificed as previously described (Badin et al., 2013). Briefly, they were anesthetized with isoflurane, $1.5 \mathrm{ml} 100 \%$ $\mathrm{w} / \mathrm{w}$, poured on the cotton layer inside the induction chamber. After the proper level of anesthesia was confirmed by the absence of the pedal reflex, the animals were decapitated and the brains were quickly and carefully extracted (Figures 1A-C). Shortly, after decapitation the skin covering the skull was cut with a surgical blade and the two sides held under the skull with the index and thumb finger (Figures 1A,B). The skull was subsequently cut along the midline with dissection scissors towards the olfactory bulbs and removed with the forceps retracting the two halves laterally (Figures 1B,C). The brain, once extracted, was cooled and kept hydrated with ice-cold "slicing" aCSF for 1-2 minute ( $\mathrm{min}$ ) and placed on filter paper where the cerebellum was removed with a surgical blade. Finally the brain was vertically glued in the center of the vibratome disc (Figure 1D), placed into the vibratome chamber which was filled with oxygenated ice cold "slicing" aCSF and surrounded by ice (Figure 1E). After regulating the cutting distance (Figure 1F), the brain was sectioned (frequency at 6-7 and speed at 6) in three consecutive coronal sections (300 $\mu \mathrm{m}$ thick) containing BF structures, (approximately Bregma 1.20-0.20 mm; Paxinos,

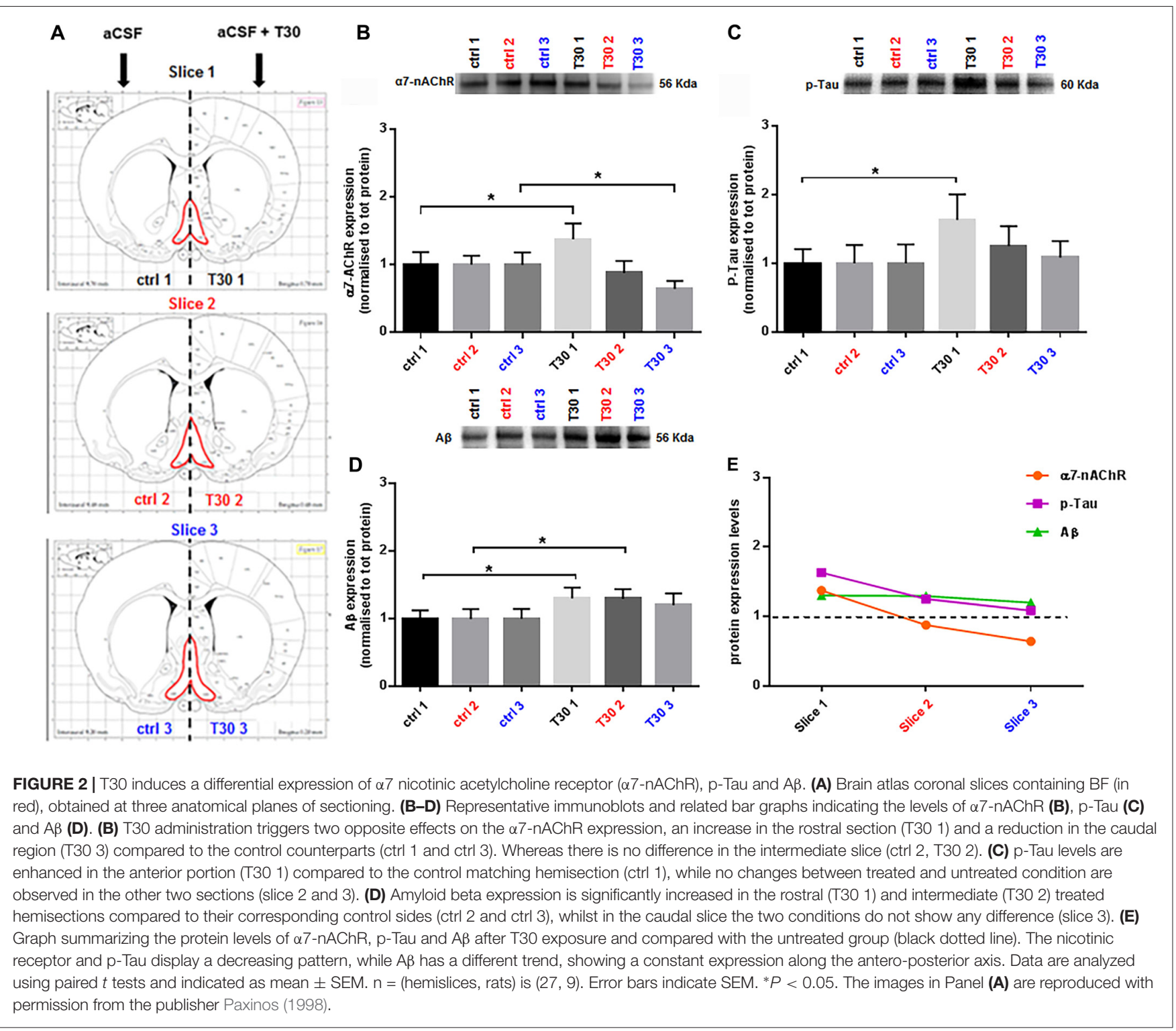


1998; Figures 1G, 2A). Following the rostro-caudal axis, the sections include the medial septum (MS), diagonal band of Broca (DBB) and, to a lesser extent, the substantia innominata (SI), containing the nucleus basalis of Meynert (NBM). Each slice was subsequently cut along the midline (Figure 1G), in order to obtain two hemisections, used respectively as control and treated preparations at the same anatomical level (Figure 2A). All hemisections were then individually placed in $5 \mathrm{ml}$ glass vials (Figure $\mathbf{1 H}$ ), where a disc of filter paper was previously inserted to prevent direct contact between the brain tissue and the glass, containing either $3 \mathrm{ml}$ of "recording" aCSF alone for the control group (Figure 1I, green frame) or enriched with 2 $\mu \mathrm{M}$ of $\mathrm{T} 30$ for the treated group (Figure 1I, red frame). From top to bottom, the vials in both conditions contained the rostral, the intermediate and the caudal region of the BF (Figure 1I). The hemisections were positioned into their corresponding vials using two different brushes, one for the control group and the other for the treated counterpart, in order to avoid any contamination. Afterwards, the vials were sealed (Figures 1J-L) and carbogen $\left(95 \% \mathrm{O}_{2}-5 \% \mathrm{CO}_{2}\right)$ was continuously provided during the experiment (Figure 1L). The procedure described in Figure 1 was performed within a time window of 10-15 min to minimize any degradation process of the tissue. The oxygen flow was frequently checked, to prevent hypoxia, and kept at the minimum to avoid fluctuation of the hemisections, which could be damaged by the oxygenating needle. After $5 \mathrm{~h}$ of incubation, the hemislices were separately transferred, with their respective brushes, into $1.5 \mathrm{ml}$ tubes containing lysis buffer. The brain tissue was then homogenized with pestles, keeping the tubes on ice. To prevent any contamination between samples, each hemisection was processed with a different pestle. The brain lysate was then centrifuged at $1000 \mathrm{~g}$ for $5 \mathrm{~min}$ at $4^{\circ} \mathrm{C}$. The supernatant was transferred to a new tube and stored at $-80^{\circ} \mathrm{C}$ until use.

\section{Western Blot Analysis}

Protein concentration was determined with Pierce Assay as previously described (Garcia-Ratés et al., 2016). Aliquots containing $10 \mu \mathrm{g} / \mu \mathrm{l}$ of proteins were prepared mixing the brain lysate with loading buffer and the denaturing agent beta-mercaptoethanol. Samples were heated at $95^{\circ} \mathrm{C}$ for $5 \mathrm{~min}$ and stored at $-80^{\circ} \mathrm{C}$ until use. Western blot procedure was performed as previously described (Garcia-Ratés et al., 2016). Briefly, proteins were separated through $4 \%-20 \%$ precast gels and blotted on PVDF membranes. After staining the membranes with Blot-FastStain to determine the transfer quality and the total protein content used for the statistical analysis, the blots were destained with warm distilled water until all the bands were removed. Then the blots were blocked in 5\% blotting grade blocker in TBS for $1 \mathrm{~h}$ at room temperature (RT), with gentle agitation. After the blocking step, the membranes were rinsed $3 \times 5$ min with TBST and incubated overnight at $4^{\circ} \mathrm{C}$ with primary antibodies diluted with $1 \%$ blocking solution prepared with TBST. The next day, the membranes were thoroughly washed in TBST $5 \times 5 \mathrm{~min}$, then incubated for $1 \mathrm{~h}$ at RT with the secondary antibodies, diluted in TBST. After the incubation, the blots were rinsed $6 \times 5 \mathrm{~min}$ with TBST and 10 min with TBS and probed for protein revelation using chemiluminescent substrates. The primary antibodies, all diluted at 1:1000, were: mouse anti-phosphorylated Tau, mouse anti-Amyloid beta and rabbit anti- $\alpha 7-n A c h R$. The secondary antibodies, all HRP conjugated, were goat anti mouse (1:2000) and goat anti rabbit (1:5000).

\section{Statistical Analysis}

Protein values were normalized to total protein expression (Supplementary Figure S1; Aldridge et al., 2008; Zeng et al., 2013) and analyzed with ImageJ software (NIH, Bethesda, MD, USA). Differences in protein levels between control and treated group were determined using paired Student's $t$-test and subsequently plotted with Graphpad software (Graphpad Prism 6, San Diego, CA, USA). All data were considered significant with a $p$-value $<0.05$.

\section{Troubleshooting}

Table 1 indicates possible issues which can occur during the procedure, their related cause and suggestions to solve and avoid them.

\section{Timing}

- Brain removal: within $1 \mathrm{~min}$

- Brain preparation for sectioning (attachment to the vibratome disc and placement inside the slicing chamber): 1-2 min

- Slicing: within 5 min

- Transfer of the hemislices in the vials and starting the experiment: 1-2 min

- (During this step the slices are not oxygenated until all the lids are closed and the apparatus is connected to the oxygen source, so is important to execute it quickly).

- Experiment length: $5 \mathrm{~h}$

- Tissue transfer into the $1.5 \mathrm{ml}$ tubes and homogenization: within $10 \mathrm{~min}$

- Centrifugation of the brain lysate: $5 \mathrm{~min}$

- Transfer of the supernatant into new tubes: 1-2 min

- The time in each step, excluding the $5 \mathrm{~h}$ incubation and centrifugation, can vary depending on the experience of the researcher.

\section{Advantages and Limitations of the Protocol}

This protocol provides several advantages: (1) it maintains the anatomical site-selectivity and the physiological milieu of the living brain; (2) slices can be easily obtained for studying a specific area; (3) depending on the characteristics of the investigated region, such as size and discernible boundaries, a microdissection could be performed after the treatment, providing a more precise read out of the investigated area; (4) direct intervention, precision dosing and an untreated contralateral side from the same slice offers an accurate control; and (5) the potential reduction in the number of living animals ultimately used in behavioral studies, based on the ability of multiplexing the desired experimental conditions. The limitations are: (1) the thickness and integrity of the tissue; (2) the incubation time; and (3) severing of connections in the rostro-caudal plane. All these aspects could 
TABLE 1 | Troubleshooting.

\begin{tabular}{|c|c|c|}
\hline Problem & Possible cause & Solution \\
\hline \multirow[t]{6}{*}{$\begin{array}{l}\text { Poor quality of the } \\
\text { tissue. }\end{array}$} & $\begin{array}{l}\text { Mechanical damage during brain removal or } \\
\text { slicing. }\end{array}$ & Operate gently and precisely while handling the tissue. \\
\hline & Slow dissection and slicing. & Practise to dissect out and process faster the brain. \\
\hline & The tissue is not kept cold. & Ensure that the brain is preserved on ice cold aCSF during removal and sectioning. \\
\hline & The hemisections are floating inside the vials. & $\begin{array}{l}\text { Reduce the oxygen flow and/or move the "oxygenating" needle if too close to the } \\
\text { hemislice to avoid a direct contact which can impair the integrity of the tissue. }\end{array}$ \\
\hline & Old solutions. & Prepare frequently fresh solutions. \\
\hline & Anoxia during the experiment. & Check that the slices are constantly oxygenated. \\
\hline \multirow{5}{*}{$\begin{array}{l}\text { Absent or inconstant } \\
\text { oxygenation. }\end{array}$} & The carbogen canister is empty. & Check before starting the experiment that the oxygen is sufficient for all the steps. \\
\hline & The valves are closed. & $\begin{array}{l}\text { Control the canister and in particular the apparatus' valves, opening them before } \\
\text { starting the procedure. }\end{array}$ \\
\hline & $\begin{array}{l}\text { The tubing are not properly connected or } \\
\text { broken. }\end{array}$ & $\begin{array}{l}\text { Check periodically the condition and functionality of the components and change them } \\
\text { if damaged. }\end{array}$ \\
\hline & The "oxygenating" needle is plugged. & $\begin{array}{l}\text { Remove quickly the injection stopper from the vial and flick the needle. A piece of } \\
\text { tissue or filter paper could block the oxygen flow. }\end{array}$ \\
\hline & $\begin{array}{l}\text { The "oxygenating" needle is not immersed in } \\
\text { the aCSF. }\end{array}$ & Ensure that the needle is properly immersed within the aCSF. \\
\hline
\end{tabular}

affect biochemical, molecular or immunohistochemical analysis. However, the integrity of the tissue can be determined through immunohistochemical detection of several markers specific for neuronal viability and electrophysiology techniques as previously described (Cho et al., 2007; Badin et al., 2013).

\section{ANTICIPATED RESULTS AND DISCUSSION}

\section{T30 Treatment Affects $\alpha 7-n A c h R, p-T a u$ and $A \beta$ Levels in a Site-Specific Manner}

After 5 h, T30 exposure (Figure 2A) induced a heterogeneous expression of $\alpha 7-n A C h R$ (Figure 2B), p-Tau (Figure 2C) and $\mathrm{A} \beta$ (Figure 2D) along the $\mathrm{BF}$ rostro-caudal axis. The $\alpha 7$ receptor, showed a $38 \%$ increase in the rostral portion (slice 1 , $p=0.0310$ ) in the treated group (Figure 2B), whereas in the intermediate slice there was no difference in the two groups (slice 2, $p=0.1195$; Figure 2B). In the caudal section its levels were reduced by $36 \%$ compared to the control group (slice 3 , $p=0.0476$; Figure 2B). Phosphorylated Tau displayed higher levels, $63 \%$, in the rostral hemisection upon T30 application, (slice 1, $p=0.0158$; Figure 2C), while the other slices did not show any change between treatments (slice 2, $p=0.1014$; slice 3, $p=0.6405$; Figure 2C). $\mathrm{A} \beta$ levels were significantly increased by $30 \%$ in the anterior and intermediate portion in the treated hemisections (slice $1, p=0.0136$; slice $2, p=0.0109$ ), whereas in the posterior slice no difference was observed in the treated side above the control (slice 3, $p=0.1231$; Figure 2D). Figure 2E recapitulates the expression patterns of the three markers upon T30 administration compared to the control value (black dotted line). Furthermore, along the rostro-caudal plane, the peptide induced two different trends in the protein levels, one promoting a continuous reduction of $\alpha 7-n A C h R$ and $p$-Tau and the second displaying a similar $A \beta$ overexpression over the control (Figure 2E).

\section{DISCUSSION}

The essential feature of this procedure is the opportunity to monitor, in a time and site-dependent manner, key neurochemical events potentially underlying neuronal dysfunction in a preparation that combines the advantages of an in vivo physiological milieu, with intact brain cytoarchitecture and local synaptic network, with those of in vitro, such as precision, accessibility and control of the extracellular environment.

This protocol is an adaptation of the well-established ex vivo brain slice model for real-time recordings, widely used for electrophysiology (Sakmann and Neher, 1984; Jensen et al., 1991; Tozzi et al., 2015; Ferrati et al., 2016) or optical imaging (Grinvald and Hildesheim, 2004; Badin et al., 2013, 2016). Despite the different methods where T30 has been previously tested (Badin et al., 2013, 2016; Greenfield, 2013; Garcia-Ratés et al., 2016), we showed for the first time in this work the T30 mediated responses using a novel approach on ex vivo brain slices. In this study, our goal was to evaluate the T30 effects on the BF, over hours, in a more physiological context than tissue culture (Bond et al., 2009; Garcia-Ratés et al., 2016) and demonstrate its contribution to slower neuronal processes characterizing the pathophysiology of neurodegenerative disorders. The data presented here indicate that, following $\mathrm{T} 30$ administration, a distinct anatomical-specific expression of the three proteins occurs. The nicotinic receptor showed an increase in the rostral treated side and a decrease in the caudal one compared to the untreated group (Figure 2B, slice 1 and 3), whereas the intermediate region does not show any change between the two conditions (Figure 2B, slice 2). These results are consistent with former studies describing a T30 mediated expression of the $\alpha 7-n A C h R$ (Bond et al., 2009).

Phosphorylated Tau levels were higher only in the rostral treated hemisection compared to the control counterpart (Figure 2C, slice 1), while no variation was observed in the 
TABLE 2 | Anatomical specificity in protein expression induced by T30 administration.

\begin{tabular}{|c|c|c|c|c|c|c|}
\hline \multirow[t]{2}{*}{$\begin{array}{l}\text { AD } \\
\text { hallmarks }\end{array}$} & \multicolumn{2}{|c|}{$\begin{array}{c}\text { Slice } 1 \\
\text { (rostral) }\end{array}$} & \multicolumn{2}{|c|}{$\begin{array}{c}\text { Slice } 2 \\
\text { (intermediate) }\end{array}$} & \multicolumn{2}{|c|}{$\begin{array}{c}\text { Slice } 3 \\
\text { (caudal) }\end{array}$} \\
\hline & ctrl 1 & T30 1 & ctrl 2 & T30 2 & ctrl 3 & T30 3 \\
\hline$\alpha 7-n A C h R$ & 1 & + & 1 & $=$ & 1 & - \\
\hline p-Tau & 1 & + & 1 & $=$ & 1 & $=$ \\
\hline$A \beta$ & 1 & + & 1 & + & 1 & $=$ \\
\hline
\end{tabular}

The protein levels are shown comparing the amount observed in the treated hemisections with their control counterparts, following the rostro-caudal axis. +, -, = indicate a significant increase, decrease or no change in protein expression in the T30 exposed group, compared to the normalized control values, designated with 1.

other slices comparing the two conditions (Figure 2C, slices 2 and 3). On the other hand, $A \beta$ was constantly overexpressed in all the T30 exposed hemisections (Figure 2D), showing a significant increase in the rostral and intermediate region above the control levels (Figure 2D, slices 1 and 2). These results suggest that the AChE-peptide could exert a pivotal role in varying the protein expression along the rostro-caudal axis (Table 2), since, in contrast, in all the controls the protein levels are similar (Figures 2B-E). Further observation was the similarity in the expression pattern shown by $\alpha 7-n A c h R$ and p-Tau, i.e., T30 administration increased their levels in the rostral portion and then a gradual decrease in the other two regions (Figure 2E). Conversely, A $\beta$ levels were similarly enhanced in all the regions compared to the other two markers (Figure 2E).

As a consequence, the influx of calcium into each BF sub-division (triggered by AChE-peptide), through a heterogeneous density of the $\alpha 7-\mathrm{nAChR}$, may in turn favor $\mathrm{p}$-Tau or $\mathrm{A} \beta$ pathways. In any event, our data are in line with earlier evidence indicating a functional interaction involving this receptor with p-Tau and A $\beta$ (Wang et al., 2000; Dineley et al., 2002; Rubio et al., 2006; Oz et al., 2013). Furthermore, several findings indicate that the $\mathrm{BF}$ nuclei are not homogenous in their physiological characteristic: they display a diverse neuronal morphology (Dinopoulos et al., 1988), as well as a differential anteroposterior distribution of GSK-3 $\beta$ (Leroy and Brion, 1999), which is indirectly activated by T30 (Bond et al., 2009) and regulates Tau phosphorylation and $A \beta$ formation (Garcia-Ratés et al., 2016). In addition, these molecular mechanisms might mediate cell death, which in $\mathrm{AD}$ occurs within the $\mathrm{BF}$ in a site specific manner (Arendt et al., 1983; Liu et al., 2015; Schmitz et al., 2016).

\section{REFERENCES}

Aldridge, G. M., Podrebarac, D. M., Greenough, W. T., and Weiler, I. J. (2008). The use of total protein stains as loading controls: an alternative to high-abundance single-protein controls in semi-quantitative immunoblotting. J. Neurosci. Methods 172, 250-254. doi: 10.1016/j.jneumeth.2008. 05.003

Arendt, T., Bigl, V., Arendt, A., and Tennstedt, A. (1983). Loss of neurons in the nucleus basalis of meynert in Alzheimer's disease, paralysis agitans and Korsakoff's disease. Acta Neuropathol. 61, 101-108. doi: 10.1007/bf00697388

Arendt, T., Brückner, M. K., Lange, M., and Bigl, V. (1992). Changes in acetylcholinesterase and butyrylcholinesterase in Alzheimer's disease resemble
In conclusion, we demonstrate that $\mathrm{T} 30$ administration on ex vivo brain slices containing $\mathrm{BF}$ alters, in a site-specific way, the expression of the $\alpha 7-\mathrm{nAChR}$, which could contribute to the modulation of $\mathrm{p}$-Tau and $\mathrm{A} \beta$. Noteworthy, it has to be considered that different concentrations of the peptide could determine dose-dependent outcomes, either increasing or decreasing the protein levels compared to the data presented in this work. Beyond the validation of the specific hypothesis explored here, this technique could open up a valuable approach to investigate a wide range of neuropathological processes, since it preserves the cytoarchitecture of the brain region, its local circuitry and the neuronal matrix over a sustained time window, thereby providing a direct and sensitive read-out of a specific level of the brain under physiological and pathological conditions.

\section{AUTHOR CONTRIBUTIONS}

EB planned and performed the experiments, analyzed the data, wrote the article. SS performed the experiments and reviewed the manuscript. A-SB showed EB the experimental procedure. SAG revised the manuscript and designed the study. All authors read and approved the final manuscript.

\section{FUNDING}

This study was funded by Neuro-Bio Ltd.

\section{ACKNOWLEDGMENTS}

We would like to thank Prof. Clive Coen (King's College London) and Dr. Giovanni Ferrati (Neuro-Bio Ltd.) for scientific observations and proof reading the article.

\section{SUPPLEMENTARY MATERIAL}

The Supplementary Material for this article can be found online at: http://journal.frontiersin.org/article/10.3389/fncel.2017.002 91/full\#supplementary-material

FIGURE S1 | Staining of the total protein expression used for statistical analysis. (A-C) Representative immunoblots showing the whole protein content used to normalize the levels of $\alpha 7-n A C h R(\mathbf{A}), p-T a u(B)$ and $A \beta(\mathbf{C})$.

embryonic development-A study of molecular forms. Neurochem. Int. 21, 381-396. doi: 10.1016/0197-0186(92)90189-x

Arendt, T., Brückner, M. K., Morawski, M., Jäger, C., and Gertz, H. J. (2015). Early neurone loss in Alzheimer's disease: cortical or subcortical? Acta Neuropathol. Commun. 3:10. doi: 10.1186/s40478-015-0187-1

Auld, D. S., Kornecook, T. J., Bastianetto, S., and Quirion, R. (2002). Alzheimer's disease and the basal forebrain cholinergic system: relations to $\beta$-amyloid peptides, cognition, and treatment strategies. Prog. Neurobiol. 68, 209-245. doi: 10.1016/S0301-0082(02)00079-5

Badin, A. S., Eraifej, J., and Greenfield, S. (2013). High-resolution spatiotemporal bioactivity of a novel peptide revealed by optical imaging in rat orbitofrontal cortex in vitro: possible implications for neurodegenerative 
diseases. Neuropharmacology 73, 10-18. doi: 10.1016/j.neuropharm.2013. 05.019

Badin, A. S., Morrill, P., Devonshire, I. M., and Greenfield, S. A. (2016). (II) Physiological profiling of an endogenous peptide in the basal forebrain: age-related bioactivity and blockade with a novel modulator. Neuropharmacology 105, 47-60. doi: 10.1016/j.neuropharm.2016.01.012

Bond, C. E., Zimmermann, M., and Greenfield, S. A. (2009). Upregulation of $\alpha 7$ nicotinic receptors by acetylcholinesterase c-terminal peptides. PLoS One 4:e4846. doi: 10.1371/journal.pone.0004846

Cho, S., Wood, A., and Bowlby, M. R. (2007). Brain slices as models for neurodegenerative disease and screening platforms to identify novel therapeutics. Curr. Neuropharmacol. 5, 19-33. doi: $10.2174 / 157015907780077105$

De Strooper, B., and Karran, E. (2016). The cellular phase of Alzheimer's disease. Cell 164, 603-615. doi: 10.1016/j.cell.2015.12.056

Dineley, K. T., Bell, K. A., Bui, D., and Sweatt, J. D. (2002). $\beta$-amyloid peptide activates $\alpha 7$ nicotinic acetylcholine receptors expressed in Xenopus oocytes. J. Biol. Chem. 277, 25056-25061. doi: 10.1074/jbc.M200066200

Dinopoulos, A., Parnavelas, J. G., Uylings, H. B., and Van Eden, C. G. (1988). Morphology of neurons in the basal forebrain nuclei of the rat: a golgi study. J. Comp. Neurol. 272, 461-474. doi: 10.1002/cne.902720402

Ferrati, G., Martini, F. J., and Maravall, M. (2016). Presynaptic adenosine receptormediated regulation of diverse thalamocortical short-term plasticity in the mouse whisker pathway. Front. Neural Circuits 10:9. doi: 10.3389/fncir.2016. 00009

Garcia-Ratés, S., Morrill, P., Tu, H., Pottiez, G., Badin, A. S., TormoGarcia, C., et al. (2016). (I) Pharmacological profiling of a novel modulator of the $\alpha 7$ nicotinic receptor: blockade of a toxic acetylcholinesterase-derived peptide increased in Alzheimer brains. Neuropharmacology 105, 487-499. doi: 10.1016/j.neuropharm.2016.02.006

Greenfield, S. (2013). Discovering and targeting the basic mechanism of neurodegeneration: the role of peptides from the c-terminus of acetylcholinesterase: non-hydrolytic effects of ache: the actions of peptides derived from the c-terminal and their relevance to neurodegenerat. Chem. Biol. Interact. 203, 543-546. doi: 10.1016/j.cbi.2013.03.015

Greenfield, S. A., Day, T., Mann, E. O., and Bermudez, I. (2004). A novel peptide modulates $\alpha 7$ nicotinic receptor responses: implications for a possible trophictoxic mechanism within the brain. J. Neurochem. 90, 325-331. doi: 10.1111/j. 1471-4159.2004.02494.x

Greenfield, S., and Vaux, D. J. (2002). Parkinson's disease, Alzheimer's disease and motor neurone disease: identifying a common mechanism. Neuroscience 113, 485-492. doi: 10.1016/s0306-4522(02)00194-x

Grinvald, A., and Hildesheim, R. (2004). VSDI: a new era in functional imaging of cortical dynamics. Nat. Rev. Neurosci. 5, 874-885. doi: 10.1038/nrn1536

Herrup, K. (2015). The case for rejecting the amyloid cascade hypothesis. Nat. Neurosci. 18, 794-799. doi: 10.1038/nn.4017

Jensen, M. S., Lambert, J. D. C., and Johansen, F. F. (1991). Electrophysiological recordings from rat hippocampus slices following in vivo brain ischemia. Brain Res. 554, 166-175. doi: 10.1016/0006-8993(91)90185-x

Leroy, K., and Brion, J.-P. (1999). Developmental expression and localization of glycogen synthase kinase-3 $\beta$ in rat brain. J. Chem. Neuroanat. 16, 279-293. doi: 10.1016/s0891-0618(99)00012-5

Liu, A. K. L., Chang, R. C. C., Pearce, R. K. B., and Gentleman, S. M. (2015). Nucleus basalis of meynert revisited: anatomy, history and differential involvement in Alzheimer's and Parkinson's disease. Acta Neuropathol. 129, 527-540. doi: 10.1007/s00401-015-1392-5

Mesulam, M. (2004). The cholinergic lesion of Alzheimer's disease: pivotal factor or side show? Learn. Mem. 11, 43-49. doi: 10.1101/lm.69204

Mesulam, M. M., Mufson, E. J., Wainer, B. H., and Levey, A. I. (1983). Central cholinergic pathways in the rat: an overview based on an alternative nomenclature (Ch1-Ch6). Neuroscience 10, 1185-1201. doi: 10.1016/03064522(83)90108-2

Oz, M., Lorke, D. E., Yang, K.-H. S., and Petroianu, G. (2013). On the interaction of $\beta$-amyloid peptides and $\alpha 7$-nicotinic acetylcholine receptors in Alzheimer's disease. Curr. Alzheimer Res. 10, 618-630. doi: 10.2174/15672050113109990132

Paxinos, G. W. (1998). The Rat Brain in Stereotaxic Coordinates. 4th Edn. San Diego, CA: Elsevier.

Rubio, A., Pérez, M., and Avila, J. (2006). Acetylcholine receptors and tau phosphorylation. Curr. Mol. Med. 6, 423-428. doi: $10.2174 / 156652406777435444$

Sakmann, B., and Neher, E. (1984). Patch clamp techniques for studying ionic channels in excitable membranes. Annu. Rev. Physiol. 46, 455-472. doi: 10.1146/annurev.ph.46.030184.002323

Schliebs, R., and Arendt, T. (2011). The cholinergic system in aging and neuronal degeneration. Behav. Brain Res. 221, 555-563. doi: 10.1016/j.bbr.2010. 11.058

Schmitz, T. W., Nathan Spreng, R., Weiner, M. W., Aisen, P., Petersen, R., Jack, C. R., et al. (2016). Basal forebrain degeneration precedes and predicts the cortical spread of Alzheimer's pathology. Nat. Commun. 7:13249. doi: 10.1038/ncomms13249

Small, G. W., and Greenfield, S. (2015). Current and future treatments for Alzheimer disease. Am. J. Geriatr. Psychiatry 23, 1101-1105. doi: 10.1016/j.jagp. 2015.08.006

Tozzi, A., Sclip, A., Tantucci, M., de Iure, A., Ghiglieri, V., Costa, C., et al. (2015). Region- and age-dependent reductions of hippocampal long-term potentiation and NMDA to AMPA ratio in a genetic model of Alzheimer's disease. Neurobiol. Aging 36, 123-133. doi: 10.1016/j.neurobiolaging.2014. 07.002

Wang, H.-Y., Lee, D. H. S., D’Andrea, M. R., Peterson, P. A., Shank, R. P., and Reitz, A. B. (2000). $\beta$-Amyloid1-42 binds to $\alpha 7$ nicotinic acetylcholine receptor with high affinity. J. Biol. Chem. 275, 5626-5632. doi: 10.1074/jbc.275.8.5626

Zeng, L., Guo, J., Xu, H.-B., Huang, R., Shao, W., Yang, L., et al. (2013). Direct blue 71 staining as a destaining-free alternative loading control method for western blotting. Electrophoresis 34, 2234-2239. doi: 10.1002/elps. 201300140

Conflict of Interest Statement: The authors declare competing financial interest. SAG is the founder and CEO of Neuro-Bio Ltd, a privately owned Company and holds shares in the Company. EB and A-SB are employees of the Neuro-Bio Ltd. SS is an undergraduate student at the University of Bristol, on industrial placement with Neuro-Bio for 9 months.

Copyright (c) 2017 Brai, Stuart, Badin and Greenfield. This is an open-access article distributed under the terms of the Creative Commons Attribution License (CC BY). The use, distribution or reproduction in other forums is permitted, provided the original author(s) or licensor are credited and that the original publication in this journal is cited, in accordance with accepted academic practice. No use, distribution or reproduction is permitted which does not comply with these terms. 